IRSH 49 (2004), pp. I04-II 4 DOI: I0.10I7/S002085900300I39I

(C) 2004 Internationaal Instituut voor Sociale Geschiedenis

\title{
Mechanisms, Processes, and Contexts
}

\author{
KNUT KJELDSTADLI
}

The plan of Dynamics of Contention embraces several goals. The first is to revitalize social-movement theory, to make it more dynamic, to transcend sharp distinctions between (for example) actors and trajectories. The second is to tear down the barriers between subdisciplines in social science such as social-movement theory and the study of nationalisms. These are conventional demarcations which the authors see as arbitrary and counterproductive to new insights that may be gained within a broader field of contentious politics. Finally the centrepiece: the authors aim to develop an explanatory strategy that avoids two pitfalls - particularistic history and sweeping generalizations in the tradition of Carl Hempel's covering law model. They propose the following solution. First, identify a number (not too large) of causal mechanisms that are at work in different times and places. Secondly, examine whether these mechanisms link regularly, whether they concatenate into what the authors call "robust processes", i.e. processes that may be identified in a number of different historical "episodes". An "episode" is something unique and circumscribed, not something ephemeral. On the other hand, an episode of nation-building may last for years. The authors' ambition seems to be to offer lean and muscular, but not parsimonious, explanations. To use their own words, their programme aims to "uncover recurring sets of mechanisms that combine into robust processes which, in turn, recur over a surprising number and broad range of episodes" (p. 3I4).

In other words, they aim to develop a toolkit with the potential to be used for analysing contentious politics in general. We might imagine contentious politics as the game of chess - chess in general - whereas the episode is one particular game of chess; a combination of moves such that the gambit can be seen as a process, whereas mechanisms are like the individual moves that are possible in the course of the game.

This approach has a number of advantages. The first is a moral one. It takes strength of character to revise one's intellectual oeuvre in such a profound and radical way as these authors have done. Here are the founding fathers of the dominant line in social-movement theory, severely criticizing that very body of literature - for being too static, for its focus on one actor at the time, for neglecting questions of how a certain opportunity structure opens a certain repertoire of contention that 
through a framing (interpretative) process results in contentious interaction. Another admirable trait of these authors is the smoothness of their collaboration. With three minds at work one might have expected the text to be more of a bricolage than a uniform sculptural block. But the text is in this respect seamless: if the aim is to encourage intellectual exchange, this seems like a model project.

The book is also an intellectual tour de force, written with great verve and packed with insights. It is also packed densely with concepts - so densely, in fact, that the present reader doubts whether he has really digested all of them.

Empirically we are offered in all seventeen accounts of contentious politics varying greatly in time, geography, content, and outcome. The authors draw on primary research by other scholars, but condense their results into a series of very well-informed and precise analytical narratives. Along the road there are important insights to be gained, some of them peripheral to the main argument. For example, there is a subtle discussion of identity formation linked to the Indian case (p. I30). There are illuminating insights on how to tell a strong state from a weak state: the introduction of direct rule, the penetration of the periphery, the standardization of practises and finally instrumentation, and an increasing availability of the means to carry out intended policies (p. 78). Many other instances could be cited.

The book is well structured, developing its arguments step by step. Its clarity could profitably serve as a model for other specialists. An important component of its methodology is the comparison of pairs of episodes belonging to the same logical class (e.g. nation-building), but with very divergent courses and outcomes. The aim is to investigate or demonstrate how the same mechanisms may work "in substantially divergent periods, places and regimes" (p. 82).

The theory behind the work also has some appealing aspects. For one thing, its approach is determinedly relational rather than structural, rationalist, phenomenological, or cultural (see p. 2I). I am particularly pleased with the authors' conception of identity formation as a social phenomenon which develops through relationships between people, rather than in the minds of individual self-contained actors (pp. 57, I30).

The process perspective is another strength, implying interaction between several actors who are simultaneously making and undergoing changes. This dynamic and less predictable kind of analysis is contrasted with models implying more or less predetermined stages in the development of a movement, such as the "movement-career" model, which assumes that movements will more or less inevitably tend to become bureaucratic and statist. Another model in for criticism is the idea of protest cycles, which invites a too mechanical view of the transitions between stages in the cycle (pp. 63f). 
A third valuable contribution is the authors' effort to break down barriers between studies of social movements, revolutions, nationbuilding, and democratization, and to see all these phenomena as varieties of contentious politics. I am inclined to favour such an overall evaluation. It is evident that similar mechanisms - such as "brokerage", whereby two sites or groups of actors are linked - are at work both in the mobilization around social movements and in nation-building. Nonetheless, a heretical counterthought presents itself: are these similarities most evident if we observe fairly abstract mechanisms, abstract in the theoretical sense of having few necessary criteria? "Competition", understood as rivalry for power between contenders, is surely a feature of most political systems. As soon as we get more specific, add criteria or variables, make a mechanism "richer", we find fewer specimens fitting the category. "Elite defection" becomes less frequent, not to speak of mechanisms like the one described (p. 275) as "bureaucratic containment of previously autonomous military forces". This mechanism surely occurs more frequently in some forms of contentious politics than in others. We still need typologies, to my mind. Even if we shun reified categories, we should not abandon interest in what distinguishes the prototypical peculiarities of a social movement from those of a revolution. Social movements constitute a family of phenomena that differs from the family of revolutions, or at least that is so in my experience.

The bulk of the analysis in this volume is concerned with episodes that have taken place primarily within national frameworks. The authors argue convincingly that the same approaches are also valid at local level. They also claim en passant that the same approaches are relevant to transnational phenomena (pp. 33, 337). I am inclined to agree: we should look forward to further work along these lines.

Most important of all, to my mind, is the effort to develop a version of what could be called "local causality" - local in both a temporal and a spatial sense. The covering law model may be stone dead, but we still need a concept of causality. Otherwise, we are left either with intentional or phenomenological explanations that are patently unable to explain collective or process phenomena, or with a theory of contingency and randomness that can offer no intelligible explanation of recurrent phenomena and social patterns. The authors' solution is, as already mentioned, to look for recurrent mechanisms that sometimes combine into what they call "robust processes", robust in the sense that they can be detected in a number of historical "episodes". They do not claim that any particular mechanism or cluster of mechanisms is a necessary condition for a particular outcome; but faced with certain phenomena, such as a 
successful revolution, "it is difficult to imagine such outcomes in the absence of significant regime defections" (p. 207).

However, some questions need to be asked about the notions of mechanisms, processes, and episodes, and I shall concentrate on these central concepts. The drift of my questions may seem more critical than my actual appreciation of the book; I console myself by invoking Hegel's dictum that negation, not confirmation, is the prime mover.

Below I list the mechanisms that occur in the text. I have tried to categorize them according to the authors' distinction (p. 25) between cognitive, relational, and environmental (background) mechanisms. ${ }^{2}$

Cognitive mechanisms:

- framing of a dispute (p. 28; not further elaborated in the text, but a well-established term in social-movement theory);

- category formation (p. I43, with the "submechanisms" of invention, borrowing, and encounter);

- attribution of similarity (p. 334);

- identity shift, "alteration in shared definitions of a boundary between two political actors and of relations across that boundary" (p. I62);

- identity threat (p. 262, not elaborated);

- reinforcement of commitment (p. 29, not further elaborated);

- attribution of opportunity and threat, i.e. interpreting something as a threat or opportunity (p. 46).

Environmental mechanisms:

- opportunity spirals (p. 243);

- infringement of elite interests (p. 199);

- suddenly imposed grievances, "singular events that dramatize and heighten the political salience of particular issues" (p. 202).

Relational mechanisms:

- object shift, "alteration in relations between claimants and objects of claims” (p. I44);

- innovatory forms of collective action;

- tactical innovation (p. 262; not elaborated, but probably meaning the same as "innovation");

- social approbation, to create or transform an organization (p. 47);

- diffusion of contention to new sites and actors along established lines of interaction (p. 323);

- emulation, "collective action modelled on the actions of others" (p. 335);

2. I am not sure whether I have found them all or classified them properly. It would have been helpful if the authors themselves had included an overview. 
- brokerage, "linking of two or more currently unconnected social sites" (p. 333);

- certification, "validation of actors, their performances, and their claims by external authorities" (p. I45);

- decertification, "withdrawal of such validation by certifying agents" (p. I2I);

- competition (for power) (p. 245);

- escalation (of conflict) through object shift (p. I49);

- repression (pp. 69, 262);

- radicalization, increasing contradiction across a boundary (p. I62);

- convergence or the "radical flank effect": radicalization on the flanks drives less extreme political actors into closer alliances (p. I62).

To these may be added twenty-one mechanisms listed only in connection with democratization (p. 275). Among these the following are singled out for analysis:

- coalition formation across classes (p. 264; also called a process);

- central cooptation of intermediaries (p. 264);

- dissolution of patron-client networks (p. 264).

The definition and listing of mechanisms both raise questions. Some are within the authors' paradigm, others are more critical of the project.

First: what is a mechanism? The authors conceive mechanisms generally as transformational, as "events that alter relations among some specified set of elements" (p. 24). It is not clear why reproductive or restorative developments should thus be excluded from the concept. It might, of course, be claimed that true contentious politics somehow always aim at a change. But often the old order is actually reinstalled, and may even be dependent on periodic contention, just as carnivals are seen as safety valves. As the authors remark, out of 709 attempts at revolution only a handful actually succeeded.

The distinction between mechanisms and processes is not clear, at least not to me. For instance, on p. 26 the shift of population and voters to the west before the American Civil War is called an "environmental mechanism"; to my mind it is more apt to call it a demographic process. "Coalition formation across classes" is called both a mechanism and a process. I shall not quibble to much about the distinction: the authors themselves state that "[i]t is arbitrary, for example, whether we call brokerage a mechanism, a family of mechanisms or a process" (p. 27). But this is, nevertheless, an important part of the argumentative architecture: only when mechanisms combine to form processes do they "produce similar [...] transformations of [...] elements" (p. 24), and finding such "robust processes" is an explicit goal.

Neither is the distinction between process, trend, or development and 
mechanism always obvious on the microlevel. Things which the authors claim as (causal) mechanisms sometimes seem more like shorthand descriptions of miniprocesses. Take for instance "repression", defined as "efforts to suppress either contentious acts or groups and organizations responsible for them" (p. 69). This is undeniably a recurring phenomenon. But why is it a "mechanism"? And where is the causality? The same applies to notions like "radicalization" or "competition", both of which describe a trend without actually specifying how one element is linked to or works on another.

The list offered ranges between mechanisms that are abstract (few criteria) and therefore fairly general and (present in many instances) and very specified mechanisms. Theoretically, this is not a problem; the same phenomenon may, of course, be classified and studied at various levels of abstraction. However, a more explicit discussion might be helpful. On what level of abstraction do concepts "work best"? Which strategy is more useful: to concentrate on a few "powerful" tools or to develop specialized equipment?

A reliance on more abstract mechanisms creates the same impression as game theory: concepts such as "chicken", or "the prisoner's dilemma”, or the peasant paradox are applicable to many situations. It is possible to demonstrate that a Bedouin tending his camels in a drought period in the Mahgreb faces the same structural problem as a Norwegian small farmer in the agrarian crisis of the I930s. To raise more camels will endanger the vegetation, so the collectively rational strategy is to limit camel numbers. But the individual Bedouin will still be tempted to take on another camel. To the individual farmer it seems economically rational to market more butter, although prices will fall if all the farmers do so. So far, we can see the similarities. But how much have we really learned about evaluations and calculations in a nomadic versus an agrarian society? Camels spell prestige and self esteem; butter does not usually engender the same pride.

From time to time the authors' demonstration of mechanisms creates a disquieting impression that we are being offered descriptions instead of explanations. We are told how something happened, but not why it happened. We learn about the channelling of a force, not so much about the force itself. For instance, we are told that brokerage took place. But why did it take place and how far did it succeed? Anyone who has been involved in efforts to form social and political alliances knows that Fortune is a fickle goddess in these matters. This may of course be read as a demand for an infinite regression, whereby an answer to a "Why?" question begets another why, like the child who ended up asking: "Why do I ask so many whys?" But I think the authors have some way to go to demonstrate that some of their mechanisms are capable of yielding results that are not general or obvious.

As I have said, several mechanisms are described in rather general or 
abstract terms. However, the notion of "submechanisms" is introduced at one point. The mechanism of "category formation", whereby actors are defined/define themselves into new categories, sometimes intersecting with the old, is said to work through three possible "submechanisms" (p. I43): invention of new categories, borrowing of categories from another site, and encounter between groups hitherto unconnected. This way of specifying how something happened looks promising; the project would have profited from similar elaborations on other mechanisms.

Secondly: what mechanisms are included? A first reflection is that the list looks rather arbitrary. Some of the mechanisms, such as brokerage and object shift, appear several times over. Some, like the long list of mechanisms on p. 275 , have a more restricted scope. Some interesting instances in the book are not elevated to the status of mechanism, although they look to me like reasonable candidates: for instance, reactions in a state of power vacuum (p. II 4 ), or negotiations as answer to power balance (p. I 53 ). Mechanisms one might expect to find (such as internal cohesion as a result of external pressure) are not mentioned. This does not really call the whole project into question. The authors would surely agree that there are other mechanisms of interest, even if they were not convinced by those I have just mentioned. But it raises the question of heuristic procedure: how does one detect - or define - a mechanism and include it in the tool kit?

I shall now pass to the combination of mechanisms into "processes". I have registered the following processes in the text:

- mobilization;

- demobilization;

- creation of actors (actor constitution);

- transformation of actors;

- identity shift;

- elite defection;

- crossclass coalition formation;

- insulation of public politics from material inequality (p. 272);

- integration of trust networks into public politics (p. 272);

- dissolution of coercive controls supporting current relations of exploitation and opportunity hoarding (p. 286);

- polarization, defined as "widening of political and social space between claimants in a contentious episode and the gravitation of previously uncommitted or moderate actors toward one, the other, or both extremes" (p. 32 I);

- "scale shift" in politics from local to translocal arenas, usually involving more actors (pp. 3I4, 33I).

I have drawn attention to the blurry line between process and mechanism. The authors define a "scale shift" as a process, while "object 
shift" is a mechanism. Surely, logic demands that a scale shift be seen as a possible aspect of object shift, where claimants' relations to the object of a claim is altered. And I would add that the processes, like the mechanisms, range from the abstract to the concrete, concrete in the sense of that they are specified and are put into context. The following problem is perhaps more important: when mechanisms are seen to occur together, is this coexistence random and contingent? Or are we witnessing a true concatenation - causal or mutually reinforcing links between mechanisms - or at least a kind of affinity, maybe due to a third factor affecting both mechanisms? The authors remark (p. 310) that "it is not clear in principle whether we are observing two or three distinct mechanisms that frequently conjoin, or have discovered a sufficiently invariant combination of cognitive, relational and environmental changes to justify treating the complex as a single robust process". This is exactly the problem that has to be addressed. If we cannot find ways of deciding when we are observing a true process and not just the accidental presence of mechanisms, the explanatory power of the authors' project is diminished.

The units that the project sets out to explain are "episodes", as opposed to continuous processes or linger sequences. Episodes are defined as "unique sequences of alterations in relations among connected elements" (p. 85). One example is the French Revolution of July 1789. But the authors are aware that episodes are not natural entities, but are "bounded and observed according to conventions established by participants, witnesses, commentators, and analysts of past episodes" (p. 29).

Their discussion on this point is somewhat sparse. ${ }^{3}$ Deciding what constitutes an episode is, in fact, a serious challenge. First: is the delineation of an episode merely a construct by a social scientist or does it have some kind of "real" existence? A radical social constructivism, assuming that elements are seen as connected only because the researcher has arbitrarily decided that they are, would undermine the entire research programme. If the combination of elements to form an episode is arbitrary, this must mean that the combination of mechanisms is equally arbitrary. The basis for claiming the existence of robust processes is eroded. The only feasible alternative is to take the stance of an ontological realist and assert that: Yes, episodes are real. This may be combined with a moderate constructivist position in epistemology, claiming that we do see real patterns, but that the particular patterns we see depend on our individual perspectives. By changing our perspective we might have discerned other

3. On p. 309, they mention two challenges when "delineating comparable events": distinguishing contention from routine politics, and understanding why a revolution or a strike is branded as such. However, the more basic problems - of isolating individual episodes within a sequences and proving that certain phenomena are not dislocated, but may be legitimately "colligated" are not really addressed. On p. 344 the problem of delineation is mentioned and singled out for further research. 
patterns. If we recognize the active role of the researcher, we need to tackle the problem of delineation with some energy.

At this point the project might benefit from a confrontation with various theories developed by historians. Let me briefly mention two. Referring to a set of events as an episode is what W.H. Walsh calls a colligation, binding elements together. The historian sees phenomena as related, claims that "different historical events can be regarded as going together to constitute a single process, a whole of which they are all parts and in which they belong together in a specially intimate way". ${ }^{4}$ The historian gathers events under a common perspective and bestows a new term, a proper name, upon them - the Renaissance, the Bolshevik Revolution, etc. The prerequisite is that the historian should be explicit about what binds the elements together. Below a certain level of cohesion we reach a threshold of fragmentation that makes it illegitimate to see something as an episode. 5 This may be a kind of likeness or affinity, as with the claim that the same mental attitude is discernible in various artistic and intellectual fields that together constitute "the Renaissance". It may be the will or project of an actor that binds the elements together. Or it may be a strong insistence by contemporaries that something constituted a unity. Finally we may see chain actions/reactions, in a local challenge-response pattern.

The other complex of theories that may enlighten a debate on episodes is the various positions taken on narration. This is not a question of simple storytelling, as our authors appear to claim (p. 310). We may discern four basic approaches:

- narration as a style, as advocated by Lawrence Stone;

- narration as a necessary literary structure in historical texts, giving meaning to the content, as claimed by Hayden White;

- narration as the historians' particular mode of explanation, as suggested by Arthur Danto or Jörn Rüsen;

- narration as a basic mode of human reasoning, as seen by Paul Ricoeur. ${ }^{6}$

The notion of episode would probably benefit from confrontation with all these approaches. However, I shall limit myself to the narrative

4. William. H. Walsh, Introduction to the Philosophy of History (London, 1967), pp. 23-24; see also idem, "Colligatory Concepts in History", in Patrick Gardiner (ed.), The Philosophy of History (London, 1974).

5. Reinhart Koselleck, Futures Past: On the Semantics of Historical Time (Cambridge, MA [etc.], 1985), p. 106.

6. Lawrence Stone, "The Revival of Narrative", Past and Present, 85 (1979), p. 3-24; Hayden White, Metahistory: The Historical Imagination in Nineteenth-Century Europe (Baltimore, MD, 1973); Arthur C. Danto, Analytical Philosophy of History (Cambridge, 1965); Jörn Rüsen, Rekonstruktion der Vergangenheit (Göttingen, I986); Paul Ricoeur, Time and Narrative. 3 vols (Chicago, IL, I984-1988). 
explanatory strategy. An analytical narrative is usually presented as an alternative to causal, covering-law models, or intentional explanations. A narrative seeks to explain a change that has taken place from one point of time to another, from one "order" to another, by relating and analysing what happened in the time between. It starts out with the object in a certain condition and then tries to register events that were contingent, i.e. not given in the object itself or pre-determined but "entered" or "met" at certain points of time. The events may be either intentional or causal: these modes of explanations are included in the narrative. Some or all of these events are seen as explanations for the change.

My point is not that the narrative strategy is superior to the mechanism/ process approach. In fact the two approaches have much in common. Dynamics of Contention also stresses the importance of contingency, e.g. of sudden events that prove to be liminal (see, e.g., p. 223). In the debate on narratives, however, some points have emerged that could profitably be included in the project of our three authors. Let me mention two insights. First: because a narrative must have a beginning and an end, the choice of starting and finishing points (in time) has a tremendous impact on the problem that is to be explained. This underlines the need to take the greatest care when choosing or delineating the episode. Secondly, narrative presents a problem with both "setting" and "sequence". We cannot claim that "we are just telling the story"; we select what to include and exclude. And the criteria for what should be included are not internally given in the story itself, not given in a story line. We must always provide a context. ${ }^{7}$

Dynamics of Contention actually provides ample scope for contextualization. The broader narratives and background descriptions make an abundance of interesting points. Some also have the potential to amount to mechanisms of general significance. In the treatment of the Mau Mau movement in Kenya, the importance of the taxi drivers as brokers is highlighted. They were a group with "weak ties" that "facilitated the spread of the movement, but not its centralized direction". This could easily be generalized into a hypothesis - that weak ties facilitate diffusion, but can also promote diversity, adaptations, and reinterpretation of a message. Another example: according to John Saul, who is quoted in the book, the denouement of the South African struggle against the apartheid regime resulted in a balance of forces that "provide a classic scenario which placed the possibility of negotiations on the agenda" (p. I53).

To be honest, I often found these more comprehensive stories more rewarding than the analyses of the mechanisms at work. This may be because the authors put less energy into what they call "environmental mechanisms", defined as "externally generated influences on conditions

7. To mention just one work that deals with this kind of question: Robert Berkhofer, Jr, Beyond the Great Story: History as Text and Discourse (Cambridge, MA [etc.], 1995). 
affecting social life" (p. 25). While due care and attention are paid to relational mechanisms (such as brokerage or certification) and cognitive mechanisms (category shift), environmental mechanisms - the setting or context - are underfocused and less well theorized. To take one example, the Communist Party of the Philippines shrank dramatically when other forces joined in the front against President Marcos. This inaction is explained by Party tradition, which shows "the overweening importance of history and culture in shaping the actions of all parties to a contentious episode" (p. I 19). The authors over and over again emphasize that the same set of mechanisms may produce very different results, depending on history, culture, and contingent chains of actions. ${ }^{8}$ It is rather puzzling that the book should offer such sparse analysis of these fields, at least compared to the analysis of mechanisms. Even if it can be shown that similar mechanisms were at work in various attempts to mobilize popular movements, to some of us the really interesting question is why some failed and others succeeded. If mechanisms cannot do this job, they do not merit more than passing attention.

8. See also p. 31 I: "Contingency also operates through the intersection of our mechanisms in ways that cannot be predicted in advance." This recalls the various attempts to overcome the inadequacies of covering-law reasoning - such as "weak" causal laws, seen as probabilities, stochastic laws, the notion of tendency and countertendency, or the unique situation seen as a specific coalescence of more general laws. 